\title{
Friction losses of cemented unclassified iron tailings slurry based on full-scale pipe-loop test
}

\author{
AX Wu University of Science and Technology Beijing, China \\ ZE Ruan University of Science and Technology Beijing, China \\ YJ Shao University of Science and Technology Beijing, China \\ JD Wang University of Science and Technology Beijing, China \\ SH Yin University of Science and Technology Beijing, China \\ SY Wang University of Science and Technology Beijing, China \\ CP Li University of Science and Technology Beijing, China
}

\begin{abstract}
Friction losses is a key parameter in the design of pipeline transportation in paste backfill. A full-scale pipe-loop test was conducted in the JCHX Paste Backfilling laboratory to investigate the friction losses of cemented unclassified iron tailings slurry. Friction losses in upward sloping pipe, vertical downward pipe, vertical upward pipe, $90^{\circ}$ long radius elbow, horizontal straight pipe and downward sloping pipe were tested simultaneously under different solid fractions. The results indicated that friction losses always increase with flow rate and solid fraction. Friction losses in the elbows are about 1.55-2.16 times that in the horizontal straight pipe, which is about 2.7-10.0 $\mathrm{kPa} \cdot \mathrm{m}^{-1}$. The pipe-loop test data can be used to analyse the rheological priorities of cemented unclassified tailings slurry. Based on the Buckingham rheological equation, an empirical formula for friction losses was established and applied to a pipe with the optimal diameter of DN $150 \mathrm{~mm}$. It can be concluded that the full-scale pipe-loop test is an effective way to investigate friction losses and the economics of design pipeline transportation.
\end{abstract}

Keywords: friction losses, unclassified tailings, pipe-loop test, pipeline transportation

\section{Introduction}

Pipeline transportation is a common method to transport tailings slurry for backfill or deposit. Friction loss is a key parameter in the design of pipeline transportation, including pipeline selection, pipeline route, pump selection and process conditions (solids concentration and mass flow rate). To investigate the friction losses of tailings slurry, experimental and simulation studies and theoretical analyses have been conducted by many researchers. L-type pipe tests and pipe-loop tests are widely used in experimental laboratory studies of friction losses (Paterson 2012; Wei et al. 2017; Wu et al. 2015). With the development of computer technology, computational fluid dynamics (CFD) has been the most common simulation method applied to the study of the transport properties of tailings slurry (Kaushal et al. 2012; Wu et al. 2018; Kumar et al. 2018). Based on rheology theory (the study of flow and deformation of materials under applied forces), the Bingham model, the Herschel-Bulkley model and other models have been applied to calculate friction losses (Hallbom 2008; Wu \& Liu 2014). Nevertheless, for thickened and paste tailings, pipe-loop tests using the actual tailings slurry are considered the most effective way to verify the model of friction losses (Paterson \& Goosen 2015). Moreover, the pipeline route usually includes different types of pipe (horizontal pipe, vertical pipe, sloping pipe and elbow).

Therefore, in this study a full-scale pipe-loop test was conducted to investigate the friction losses of cemented unclassified iron tailings slurry in different types of pipe to provide technical support for the cemented paste backfill system design at Qijiaojing Iron Mine in northwest China. 


\section{$2 \quad$ Materials and methods}

\subsection{Tailings properties}

The density of unclassified tailings sampled from Qijiaojing Iron Mine and tested by Water Pycnometer was $2,966 \mathrm{~kg} \cdot \mathrm{m}^{-3}$. The particle size distribution (PSD) of unclassified tailings was analysed by a high-performance laser particle size analyser (TopSider) produced by OMEC. As shown in Figure 1, D50 and D(3,2) are $12.855 \mu \mathrm{m}$ and $5.105 \mu \mathrm{m}$, respectively. Moreover, the content of $\leq 20 \mu \mathrm{m}$ is $64.89 \%$, indicating that the particles are ultrafine. To improve the PSD of tailings, discarding tailings with a density of $2,461 \mathrm{~kg} \cdot \mathrm{m}^{-3}$ was added to the unclassified tailings. The content of $\leq 74 \mu \mathrm{m}$ and $\leq 5 \mathrm{~mm}$ are $3.53 \%$ and $92.03 \%$, respectively. The chemical composition analysis on unclassified tailings shown in Table 1 , performed by X-ray fluorescence, is similar to the chemical composition of discharging tailings. The 32.5R Portland cement was used to produce cemented unclassified tailings.

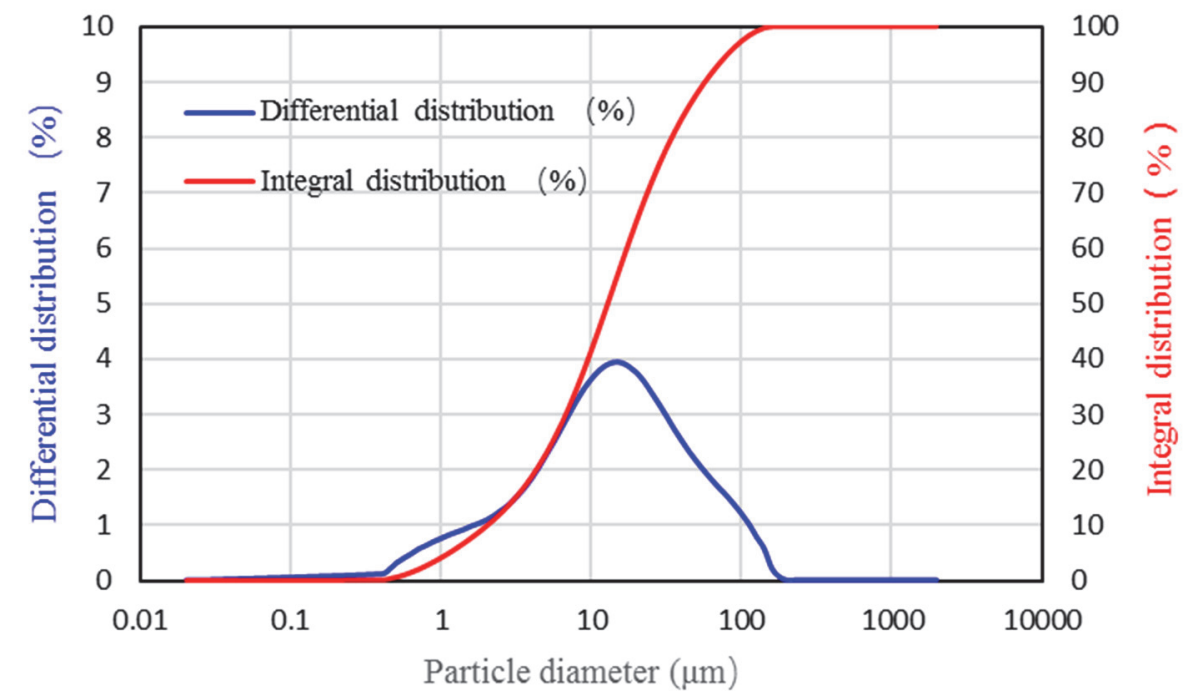

Figure 1 Particle size distribution of unclassified tailings

Table 1 Chemical composition of the tailings

\begin{tabular}{ll}
\hline Chemical composition & Content (\%) \\
\hline $\mathrm{SiO}_{2}$ & 50.63 \\
$\mathrm{Fe}_{2} \mathrm{O}_{3}$ & 25.54 \\
$\mathrm{CaO}$ & 9.39 \\
$\mathrm{MgO}$ & 5.39 \\
$\mathrm{Al}_{2} \mathrm{O}_{3}$ & 2.72 \\
$\mathrm{SO}_{3}$ & 1.92 \\
Others & 4.40 \\
\hline
\end{tabular}

\section{$2.2 \quad$ Test setup}

The full-scale pipe-loop test was conducted in the JCHX Paste Backfilling laboratory. The prepared tailings slurry was sent from the horizontal double-spiral mixer down to the PM plunger pump and pumped into the loop pipeline. The flfcontow meter and pressure meters (P1-P12) were installed in the pipeline. The four test pipelines had different diameters: DN $50 \mathrm{~mm}$, DN $100 \mathrm{~mm}$, DN $150 \mathrm{~mm}$ and DN $200 \mathrm{~mm}$, respectively. Each pipeline was arranged along a different route, including an upward sloping pipe, vertical downward pipe, 
vertical upward pipe, $90^{\circ}$ long radius elbow, horizontal straight pipe, and downward sloping pipe. The slurry finally returned to the double-spiral mixer to form a closed circuit. At both ends of each test pipe section, pressure meters were installed to detect pipe pressure in real time. All test data was collected and recorded by the distributed control system. The sketch and photographic appearance of the loop pipe are shown in Figures 2 and 3. The cement-to-tailings ratio and unclassified-to-discharging tailings ratio are 1:25 and 7:3, respectively. The pipeline used in the experiment was DN $100 \mathrm{~mm}$.

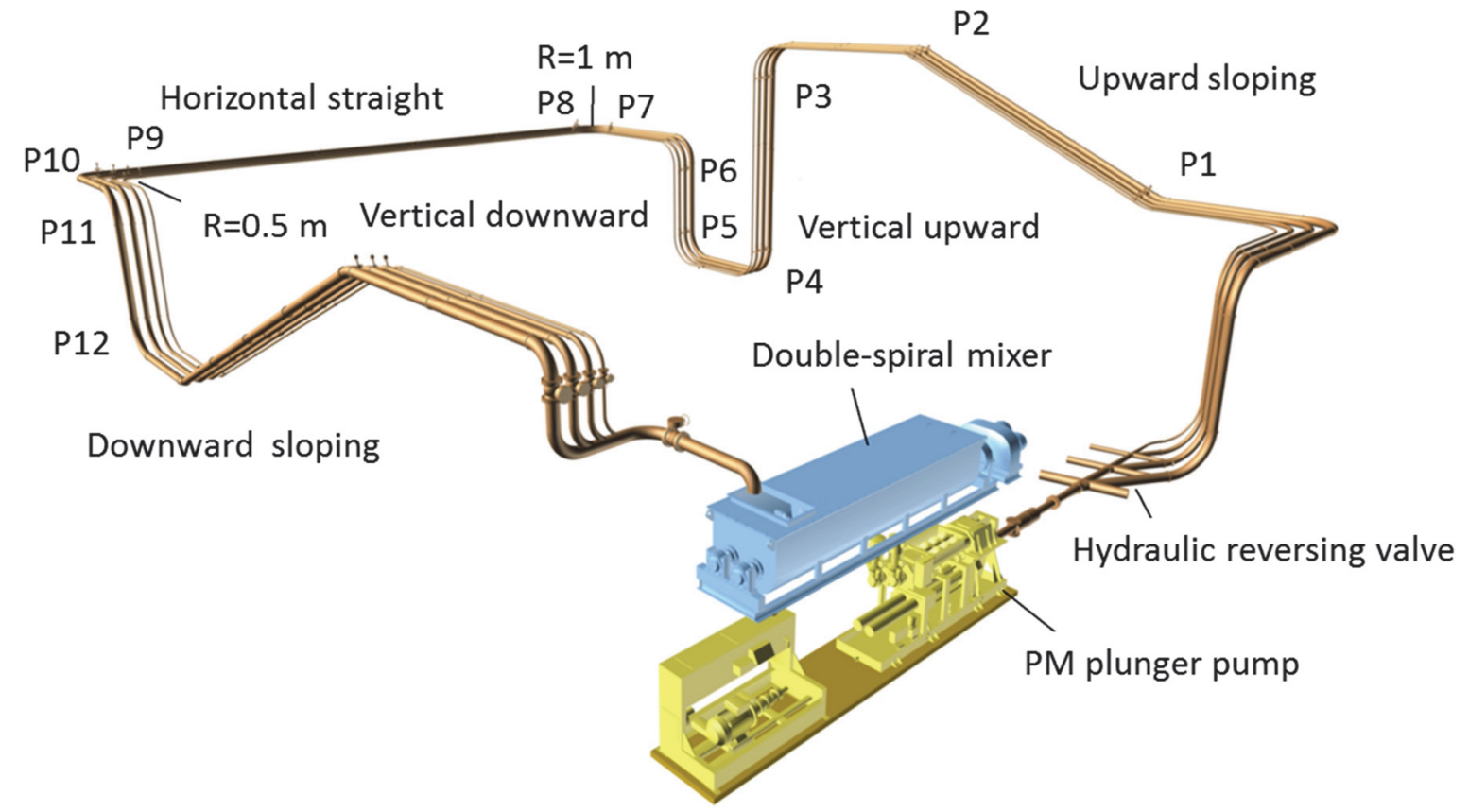

Figure 2 Sketch of the loop pipes (P1-P12 are pressure meters)

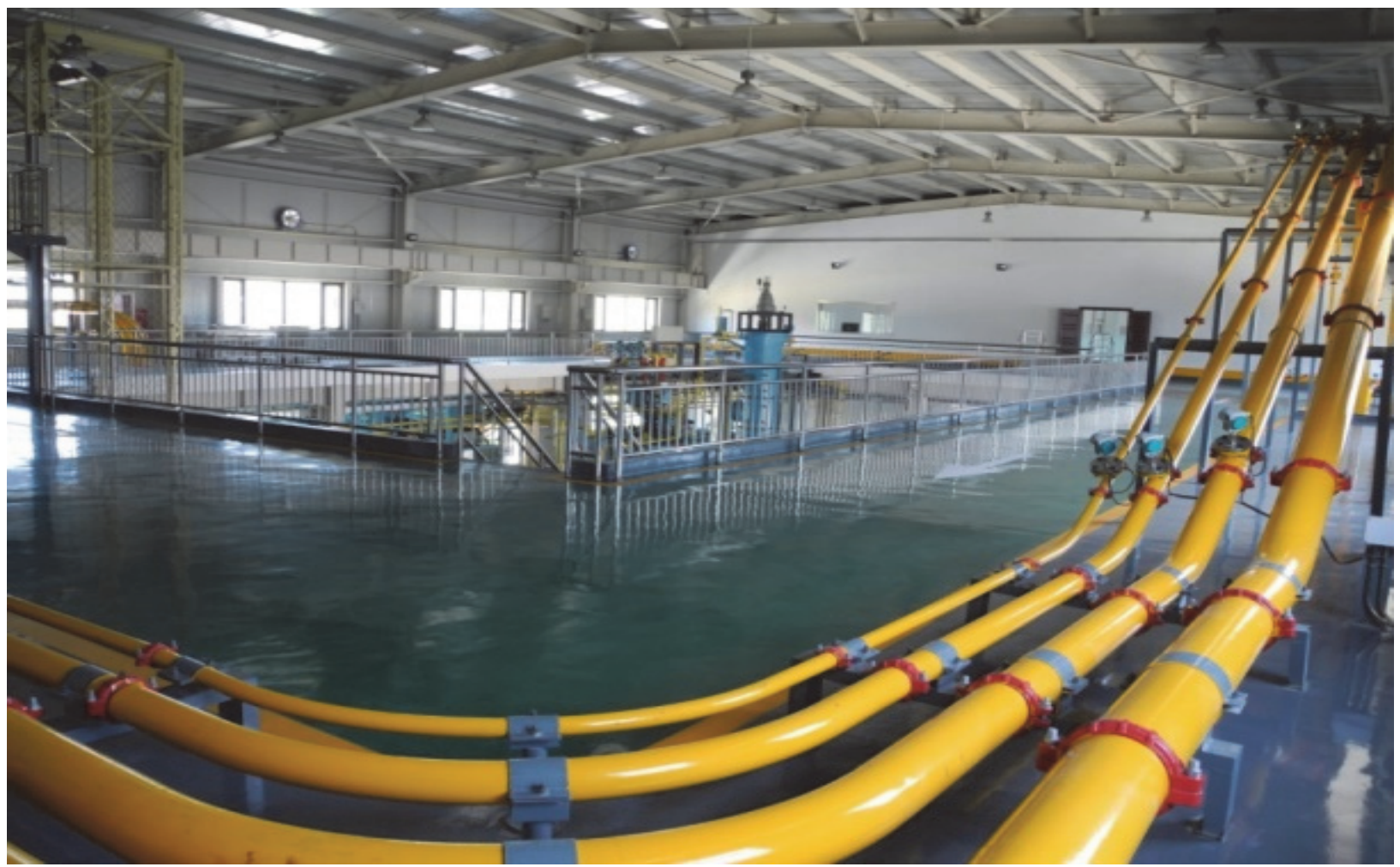

Figure 3 Photograph of the loop pipes 


\section{Results and discussion}

The purpose of the pipe-loop test is to investigate friction losses. The pressure data will be processed to analyse the friction losses and rheological properties, and establish an empirical formula for friction losses.

\subsection{Test results}

The pipe-loop test was conducted under the different solid fraction of $74.8 \mathrm{wt} \%, 76.0 \mathrm{wt} \%, 77.1 \mathrm{wt} \%$ and $78.0 \mathrm{wt} \%$. The change of flow rate and pressure at each pressure meter is shown in Figure 4 . The flow rate was increased from 23.39 to $28.80 \mathrm{~m}^{3} \cdot \mathrm{h}^{-1}, 36.84$ and $37.84 \mathrm{~m}^{3} \cdot \mathrm{h}^{-1}$. The time step for each flow rate is $300 \mathrm{~s}$. Obviously, the pressure under the different solid fraction increased with the flow rate, as expected. At the same time, the pressure data in the pipe was unstable due to the discontinuity of pump pressure; hence, the pressure distribution is similar to mechanical waves, fluctuating at a certain value. Through the periodic collection of data statistics, it was found that the pressure data agreed with a normal distribution. Therefore, the normal distribution was used to fit the data, and the pressure fluctuation curve was obtained. The median value in this curve was chosen to describe the trend of change, which is discussed in the following subsection.
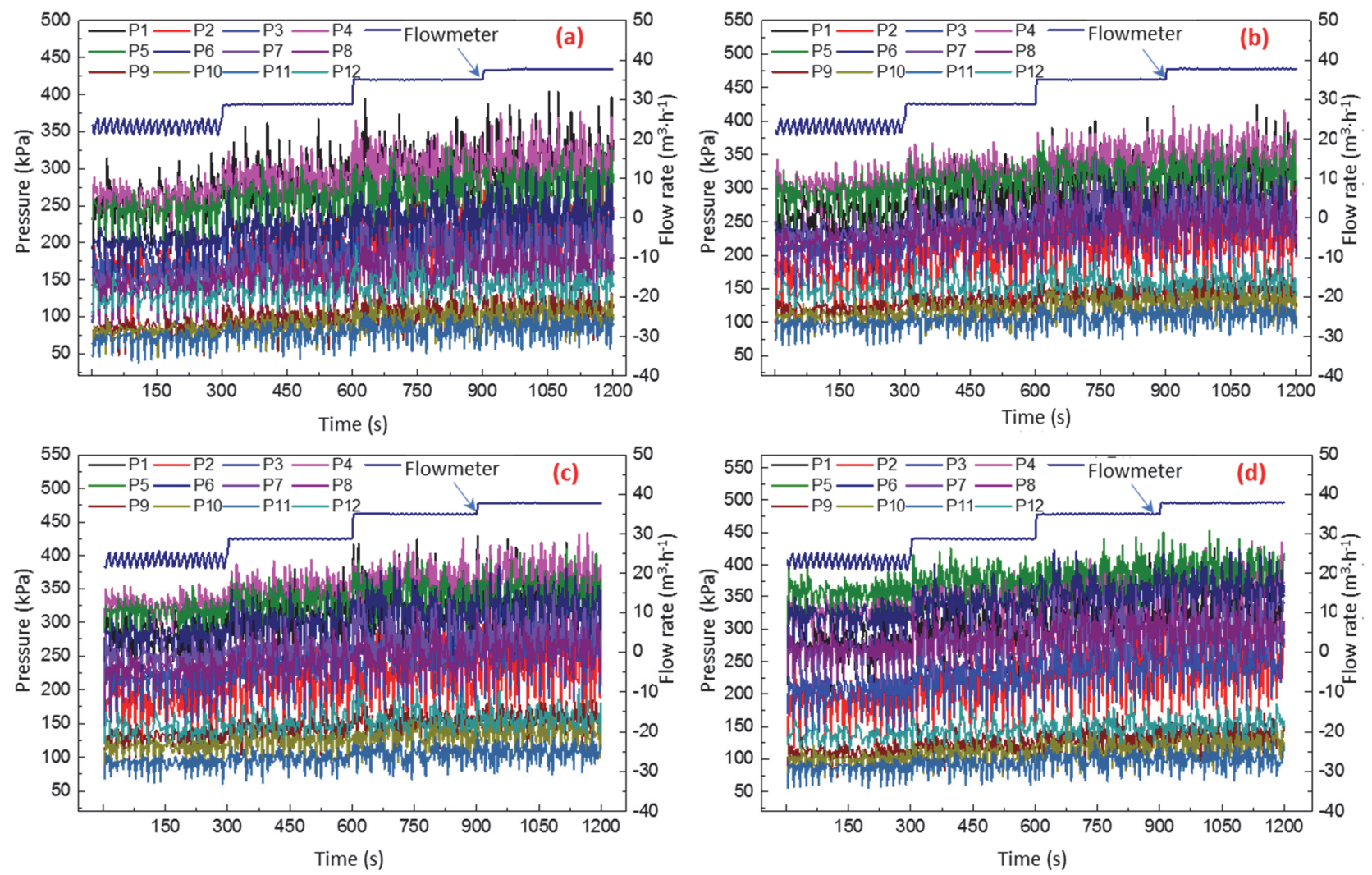

Figure 4 Pressure and flow rate curve at solid fraction of (a) $74.8 \mathrm{wt} \%$; (b) $76.0 \mathrm{wt} \%$; (c) $77.1 \mathrm{wt} \%$; (d) $78.0 \mathrm{wt} \%$

\subsection{Effect of the solid fraction on friction losses}

The friction losses in the horizontal straight pipe under different solid fractions and flow rates were analysed. The effect of the solid fraction on friction losses was shown in Figure 5. It illustrated that friction losses increased with the solid fraction, as expected. In particular, friction losses increased when the solid fraction changed from $76.0 \mathrm{wt} \%$ to $77.1 \mathrm{wt} \%$, and clearly increased when the solid fraction increased from $77.1 \mathrm{wt} \%$ to $78.0 \mathrm{wt} \%$. Therefore, to reduce transportation costs, $77.1 \mathrm{wt} \%$ or $77.0 \mathrm{wt} \%$ are considered optimal. 


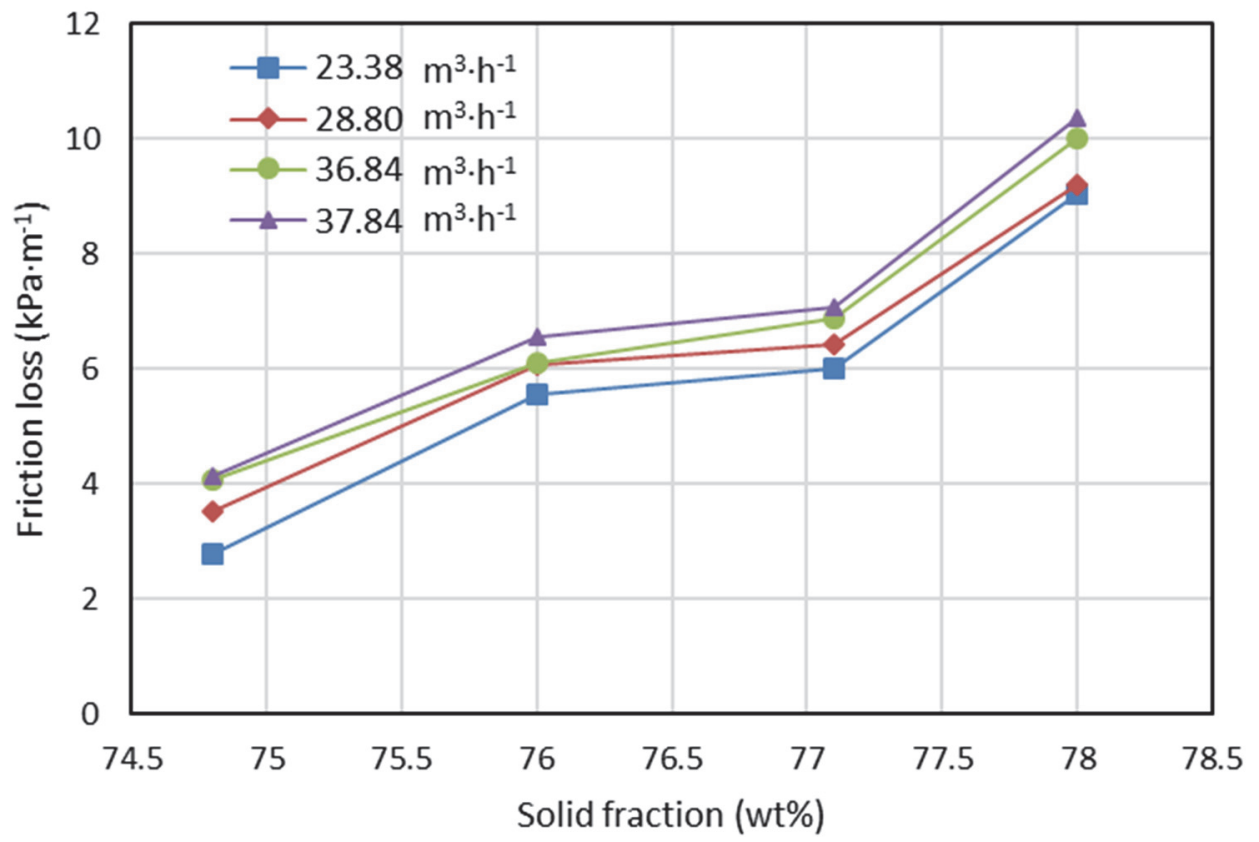

Figure 5 Effect of the solid fraction on friction losses

\subsection{Effect of the pipeline route on friction losses}

The friction losses of cemented unclassified iron tailings slurry with a solid fraction of $77.1 \mathrm{wt} \%$ in different types of pipeline route are shown in Figure 6 . The effect of the pipeline route on friction losses is significant. The ranking of friction losses in different routes is horizontal straight pipe < downward sloping pipe < upward sloping pipe < vertical downward pipe < vertical upward pipe $<90^{\circ}$ long radius elbow $(R=1 \mathrm{~m})<90^{\circ}$ long radius elbow $(R=0.5 \mathrm{~m})$. Friction losses in the downward sloping pipe, upward sloping pipe and vertical downward pipe are almost the same, and a little higher than that in the horizontal straight pipe. The friction losses in the elbow are much higher than that in the horizontal straight pipe - by about 1.55-2.16 times. It should be noted that the bigger the radius of the elbow, the higher the friction losses will be. Therefore, designers of the pipeline route should use the elbow, especially the elbow with a small radius, as little as possible, to effectively reduce friction losses.

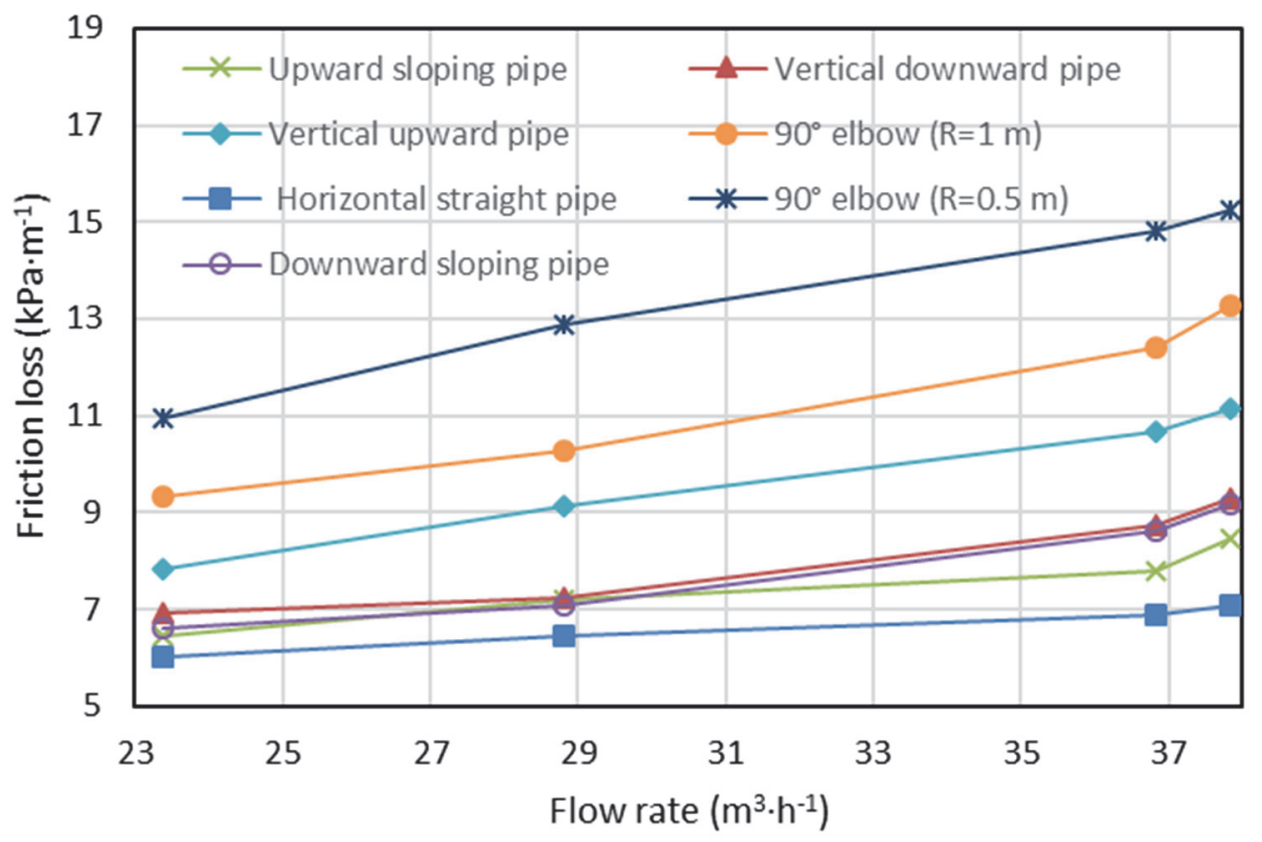

Figure 6 Effect of pipeline route on friction losses 


\subsection{Rheological properties and empirical formula for friction losses}

Rheological properties, which are useful for calculating friction losses, are the most important properties of tailings slurry in pipeline transportation. Using data from the pipe-loop test to analyse the rheological properties is a common and effective approach. Usually, thickened and paste tailings slurry is considered as Bingham fluid and the Bingham model is applied to describe the rheological properties (Equation 1).

$$
\tau=\tau_{0}+\eta \gamma
$$

where:

$$
\begin{aligned}
\tau & =\text { shear stress. } \\
\tau_{0} & =\text { yield stress. } \\
H & =\text { plastic viscosity. } \\
\nu & =\text { shear ratio. }
\end{aligned}
$$

Based on Buckingham rheological equation, the relation between friction losses and flow rate can be derived per Equation 2:

$$
\frac{D \Delta P}{4 L}=\frac{4}{3} \tau_{0}+\frac{8 v}{D} \eta
$$

where:

$$
\begin{array}{lll}
\Delta P / L & = & \text { friction losses. } \\
D \Delta P / 4 L & = & \text { shear stress. } \\
D & = & \text { diameter of the pipeline. } \\
v & = & \text { velocity of the slurry. }
\end{array}
$$

According to the friction losses of cemented unclassified iron tailings slurry with a solid fraction of $77.1 \mathrm{wt} \%$, the DP/4L-8v/D curve of the slurry can be obtained as in Figure 7. The intercept and slope of the fitted curve are the yield stress and plastic viscosity of the slurry, respectively.

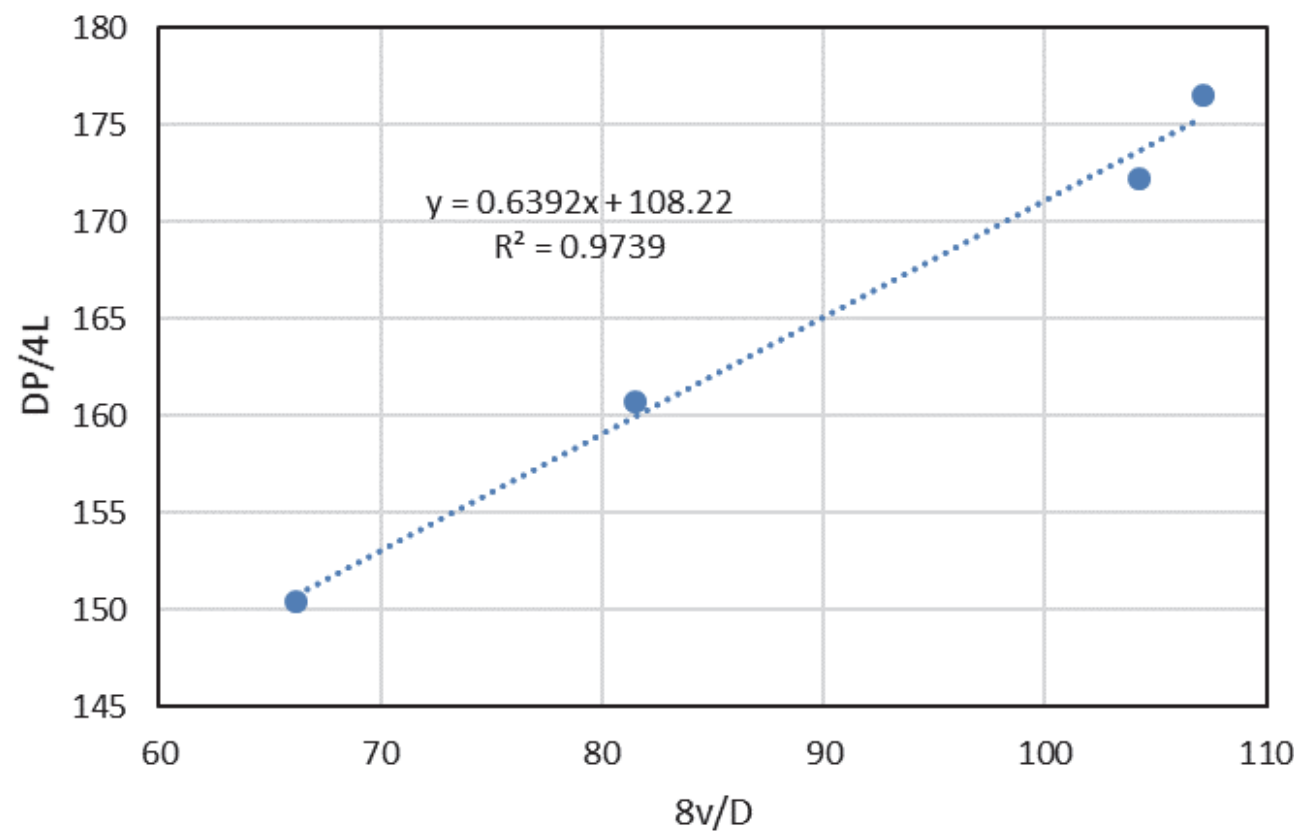

Figure 7 DP/4L-8v/D curve of tailings slurry 
From Figure 7, the rheological model of cemented unclassified iron tailings slurry is calculated using Equation 3:

$$
\tau=108.22+0.6392 \gamma
$$

Accordingly, the empirical formula for friction losses based on Buckingham rheological equation and shear stress and plastic viscosity can be derived per Equation 4:

$$
i_{h}=\frac{432.88}{D}+\frac{20.454 v}{D^{2}}
$$

where:

$$
i_{h} \quad=\text { shear stress. }
$$

\subsection{Pipe diameter selection}

The flow rate and friction losses should be considered comprehensively to select the optimal diameter of pipe. Under the given flow rate, the smaller the pipe diameter, the greater the flow velocity in the pipe, resulting in higher friction losses. On the contrary, increasing the diameter of the pipeline can reduce the friction losses of pipeline transportation and save power consumption, but the use of an excessive diameter is economically unreasonable. Based on Equation 4, the friction losses under different flow rates and pipe diameters can be calculated as shown in Figure 8. It indicates that friction losses decrease with the increase of pipe diameter. In addition, the decrease rate also decreases with the increase of pipe diameter. Especially when the diameter is more than $150 \mathrm{~mm}$, friction losses under different flow rate close to the same. Consequently, the optimal diameter can be selected as DN $150 \mathrm{~mm}$.

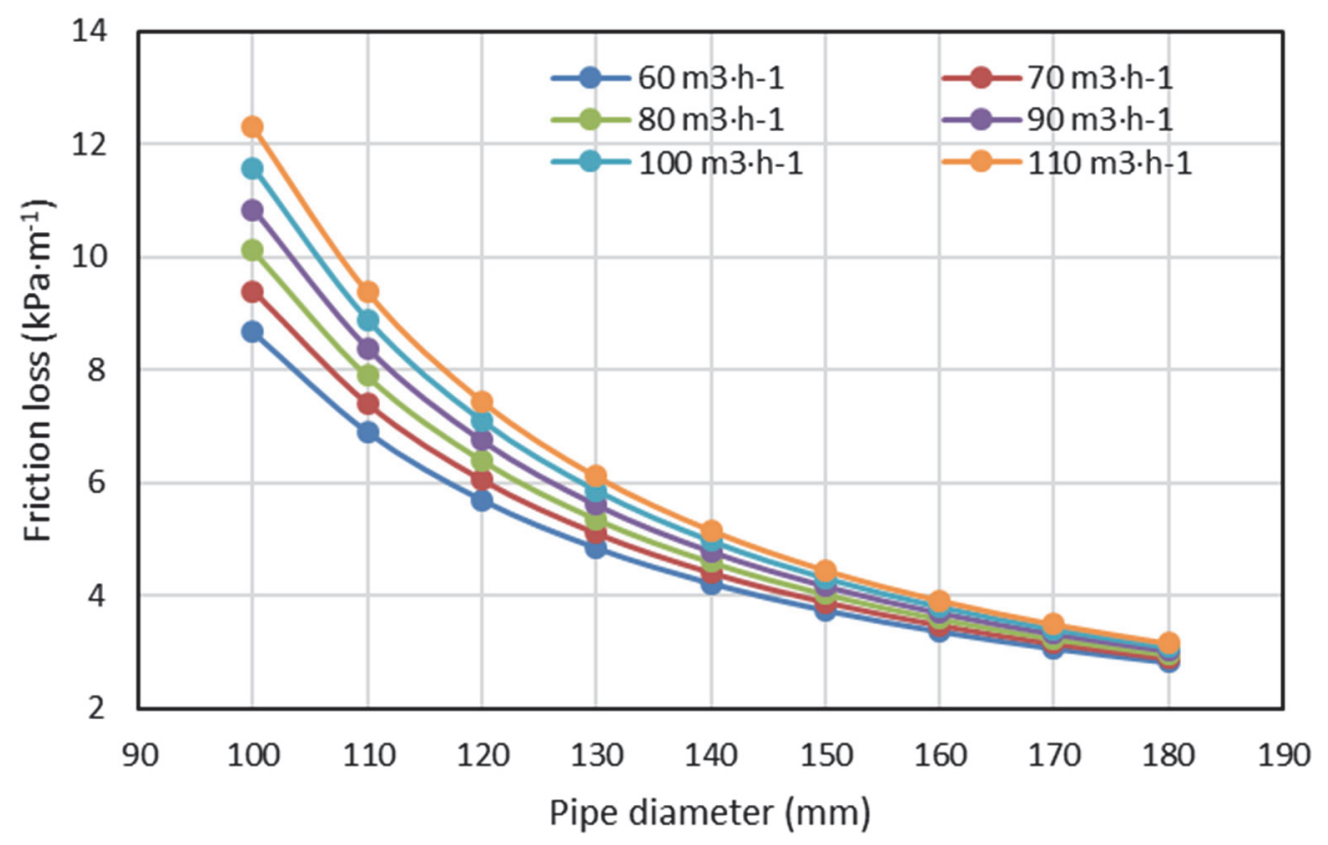

Figure 8 Change of friction losses with pipe diameter and flow rate

\section{Conclusion}

The full-scale pipe-loop test is an effective approach to verify the model of friction losses and the design of a transportation pipeline.

The friction losses always increase with flow rate and solid fraction. The friction losses in different type pipeline route are quite different. The friction in the horizontal straight pipe is about $2.7-10.0 \mathrm{kPa} \cdot \mathrm{m}^{-1}$. However, the friction losses in the elbow are much higher, which is about 1.55-2.16 times of that in the 
horizontal straight pipe. Therefore, the reasonable design of pipeline route should use the elbow, especially the elbow with a small radius, as little as possible, to reduce friction losses effectively.

Based on Buckingham rheological equation and pipe-loop test, the rheological properties were analysed.

An empirical formula for friction losses was established and the optimal diameter was selected as DN $150 \mathrm{~mm}$.

\section{Acknowledgement}

This research was funded by the State Key Research Development Program of China (No. 2018YFC0603705), the National Natural Science Foundation of China (No. 51834001). The authors gratefully acknowledge the support of the K.C. Wong Education Foundation.

\section{References}

Hallbom, DJ 2008, Pipe Flow of Homogeneous Slurry, PhD thesis, The University of British Columbia, Vancouver.

Kaushal, DR, Thinglas, T, Tomita, Y, Kuchii, S \& Tsukamoto, H 2012, 'CFD modeling for pipeline flow of fine particles at high concentration', International Journal of Multiphase Flow, vol. 43, pp. 85-100.

Kumar, N, Gopaliya, MK \& Kaushal, DR 2018, 'Experimental investigations and CFD modeling for flow of highly concentrated iron ore slurry through horizontal pipeline', Particulate Science and Technology, pp. 1-19.

Paterson, AJC 2012, 'Pipeline transport of high density slurries: a historical review of past mistakes, lessons learned and current technologies', Mining Technology, vol. 121, no. 1, pp. 37-45.

Paterson, A \& Goosen, P 2015, 'High-concentration hydraulic transport systems', in RJ Jewell \& AB Fourie (eds), Paste and Thickened Tailings: A Guide, 3rd edn, Australian Centre for Geomechanics, Perth, pp. 171-190.

Wei, C, Wang, XM, Zhang, YH \& Zhang, QL 2017, 'Paste-like cemented backfilling technology and rheological characteristics analysis based on jigging sands', Journal of Central South University, vol. 24, no. 1, pp. 155-167.

$\mathrm{Wu}, \mathrm{AX}$ \& Liu, XH 2014, 'Resistance characteristics of structure fluid backfilling slurry in pipeline transport', Journal of Central South University, vol. 45, no. 12, pp. 4325-4330 (in Chinese).

Wu, AX, Ruan, ZE, Wang, YM, Yin, SH, Wang, SY, Wang, Y \& Wang, JD 2018, 'Simulation of long-distance pipeline transportation properties of whole-tailings paste with high sliming', Journal of Central South University, vol. 25, no. 1, pp. 141-150.

$\mathrm{Wu}, \mathrm{D}$, Yang, B \& Liu, Y 2015, 'Pressure drop in loop pipe flow of fresh cemented coal gangue-fly ash slurry: experiment and simulation', Advanced Powder Technology, vol. 26, no. 3, pp. 920-927. 